\title{
INSERCIÓN LABORAL DE LA POBLACIÓN DESPLAZADA POR EL CONFLICTO ARMADO EN LA FRONTERA COLOMBO ECUATORIANA*
}

Recibido: 05 de junio de 2012 • Aprobado: 05 de octubre de 2013

\author{
Alba Jakeline Ruano Jiménez ${ }^{* *}$
}

\section{RESUMEN}

Este artículo analiza el proceso de inserción laboral de la población en situación de desplazamiento forzado que residía en la ciudad de Ipiales en el año 2010. El enfoque metodológico es etnográfico e implicó la realización de un trabajo, de campo con población en situación de desplazamiento, que duró un año. Las experiencias de inserción laboral, la competencia por un lugar en el contexto del trabajo informal y el trasegar de estas personas al llegar a la ciudad, permite visibilizar la precaria situación social y económica que enfrenta la población migrante dentro de una ciudad periférica y con escasas fuentes de generación de empleo, como lo es la ciudad de Ipiales, en el suroccidente de Colombia.

\section{PALABRAS CLAVE}

Migración forzada, economía informal, inserción laboral, redes sociales.

\section{CLASIFICACIÓN JEL}

J15, E26, I38, J18

\section{CONTENIDO}

Introducción; 1. La ciudad frontera y el contexto laboral; 2. El trabajo informal, la alternativa laboral: "el rebusque"; 3. Redes sociales y familiares;

4. Reflexiones finales; Bibliografía.

Este articulo es producto del proyecto de investigación: "Desplazamiento forzado: modos de vida y relaciones sociales en la ciudad de Ipiales (2010)". Presentado como trabajo final de grado para obtener el título de magíster en Sociología, Universidad Nacional de Colombia, aprobado en febrero de 2012. Trabajo dirigido por el antropólogo Andrés Salcedo Fidalgo de la Universidad Nacional, Bogotá, Colombia.

** Socióloga de la Universidad de Nariño, Pasto, Colombia. Especialista en Docencia Universitaria de la Universidad de Nariño, San Juan de Pasto, Colombia. Magíster en Sociología de la Universidad Nacional, Bogotá, Colombia. Docente de la Universidad de Nariño, Pasto, Colombia. Integrante del grupo multidisciplinario de investigación social GRUMIS, Universidad de Nariño, Pasto, Colombia. Correo electrónico: albajakeline@ gmail.com o ajruanoj@unal.edu.co. 


\section{LABOR INSERTION FOR THE POPULATION DESPLACED BY THE ARMED CONFLICT AT THE COLOMBIAN-ECUATORIAN BORDER}

\section{ABSTRACT}

This article analyzes the labor insertion process for the population that was forcefully displaced living at the city of Ipiales during 2010. The fieldwork had an ethnographical scope, was carried out with individuals facing forced displacement conditions and lasted for a year. The labor insertion experiences, the competition for a place in the informal market and the difficulties faced by these individuals when arriving to the city is evidence of the precocious social and economic situation faced by this migrating population within a peripheral city such as Ipiales with scarce employment generation sources located in the southwestern region of Colombia.

\section{KEY WORDS}

Forced migration, informal economy, labor insertion, social networks

\section{JEL CLASSIFICATION}

J15, E26, I38, J18

\section{CONTENT}

Introduction; 1 . The border city and the labor situation; 2. Informal labor and labor alternatives: "hustling for a job" Social and family networks; Final considerations; Bibliography

\section{INSERÇÃO TRABALHISTA DA POPULAÇÃO DESLOCADA PELO CONFLITO, FRONTEIRA COM A COLÔBIA NO EQUATOR}

\section{RESUMO}

Este artigo analisa o processo de inserção trabalhista da população em situação de deslocamento forçado que residia na cidade de Ipiales em 2010. O enfoque metodológico é etnográfico e implicou a realização de um trabalho de campo com população em situação de deslocamento que duro um ano. As experiências de inserção trabalhista, a concorrência por um lugar no contexto do trabalho informal e o trafegar destas pessoas ao chegar à cidade, permite visibilizar a precária situação social e econômica que enfrenta a população migrante dentro de uma cidade periférica e com escassas fontes de geração de emprego como o é a cidade de Ipiales, no sul ocidente da Colômbia.

\section{PALAVRAS CHAVE}

Migração forçada, economia informal, inserção trabalhista, redes sociais.

\section{CLASSIFICAÇÃO JEL}

J15, E26, I38, J18.

\section{CONTEÚDO}

Introdução; 1. A cidade fronteira e o contexto trabalhista; 2 . O trabalho informal, a alternativa trabalhista: "o rebusque"; 3 . Redes sociais e familiares; 4. Reflexiones finais; Bibliografia. 


\section{INTRODUCCIÓN}

Ipiales $^{1}$ es una ciudad de múltiples rostros, como diría Castells (2008), donde el mundo rural y el urbano se entrelazan, y donde la frontera binacional, le imprime unas características sociales, culturales y económicas particulares. Según las proyecciones de población del DANE, en 2010 el municipio de Ipiales contaba con 123341 habitantes, distribuidas así: 85791 habitantes ubicados en la cabecera municipal, y 37 550, en el resto del municipio. De esta población, según información de la misma fuente, el $27.7 \%$ se auto-reconoce como población indígena, perteneciente, en su gran mayoría, a la comunidad Pasto. A esta se suma un porcentaje no determinado de población flotante, migrantes temporales colombianos y ecuatorianos, además de los desplazados sobre los cuales se empieza a tener registro desde finales de los años noventa. Este contexto lleva a que se contemple una dinámica poblacional con tendencia al crecimiento urbano, situación que se traduce en mayor demanda de servicios públicos, mayor oferta y demanda de empleo, vivienda, consumo de energía, gas, sitios de recreación y cupos para educación, entre otros (POT, 2007, pp. 27-29).

Instituciones como Acción Social ${ }^{2}$ (2008), la Consultoría para los Derechos Humanos y el Desplazamiento -CODHES (2009)- y Pastoral Social (2010) informan que desde el año 2000 se ha incrementado el registro de población en situación de desplazamiento en la ciudad de Ipiales. Solo durante 2007 se registraron en el Sistema Único de Población Desplazada 582 personas, a quienes se suman las registradas en años anteriores y aquellas que no se registraron, algunas de las cuales se establecieron en Ipiales, otras migraron hacia otras partes del país, y un porcentaje desconocido que migra hacia el Ecuador.

En este contexto, el objetivo central del presente artículo es describir y avanzar en el análisis sociológico de los procesos de inserción laboral de la población desplaza$\mathrm{da}$, que se establece en la ciudad de Ipiales de manera temporal y/o permanente. El desarrollo del objetivo hace parte de un proceso investigativo de carácter etnográfico con población víctima de desplazamiento forzado ubicada en Ipiales. El ejercicio etnográfico propuesto por Marcus (2001, p.113) "pone atención en lo cotidiano, en el conocimiento cara a cara de comunidades y grupos" se desarrolló durante un año de trabajo de campo con esta población. En primeros seis meses se hicieron

\footnotetext{
La ciudad de Ipiales se encuentra ubicada en la frontera colombo-ecuatoriana. Es el segundo centro urbano más importante del Departamento de Nariño en Colombia, después de la capital (Pasto).

2 Entidad de la presidencia de la Republica de Colombia, que para el año 2011 se transforma dando lugar a la creación del Departamento Administrativo para la Prosperidad Social, el cual tiene como reto principal avanzar en la superación de la pobreza, la inclusión de la población vulnerable y víctima de la violencia, y la consolidación de los territorios a través de la garantía de la presencia del Estado en una senda de prosperidad y reconciliación.
} 
acercamientos a instituciones como Acción Social y Pastoral Social, y a través de estas entidades se logró la vinculación en trabajo con población desplazada ubicada en Ipiales. En el segundo semestre se compartieron espacios y momentos con 16 personas y sus familias, donde la observación participante ${ }^{3}$ y la entrevista biográfica se convierten en las principales herramientas para la producción, recogida o captación de datos sobre el terreno.

La observación participante fue un ejercicio de etnografía multilocal, en términos de trabajo de campo, como lo menciona Marcus (2001, p. 114) "el trabajo de campo tal y como es percibido y practicado habitualmente, es en sí mismo potencialmente multilocal". El trabajo de campo se llevó a cabo en primera persona; se compartieron lugares donde la población desplazada realiza su día a día, como sus viviendas, los barrios y los lugares de trabajo como las plazas de mercado y la calle; no se prepararon los ambientes ni los lugares para facilitar el trabajo investigativo; durante el período del trabajo de campo la interacción con la población fue personal y se lograron establecer relaciones de confianza que facilitaron "comprender" su mundo desde sus experiencias migratorias y sus percepciones, lo que permitió la validación de la información.

Entre las personas con la cuales se compartieron estos espacios se encuentran personas que han sido desplazadas de diferentes partes de Colombia, en su gran mayoría de municipios del mismo departamento de Nariño, como Puerres, Tumaco, Barbacoas, Cumbitara, y de la zona rural de Ipiales, y de municipios del departamento del Putumayo, como Santiago, Puerto Caicedo, Orito, La Hormiga y Puerto Asís. Estos municipios se ubican en regiones periféricas y marginales, zonas que Serje (2005) identifica como las regiones que han sido construidas como "marginales" salvajes representadas en el imaginario nacional como zonas conflictivas, de caos, de desorden, que no son reguladas de forma preponderante por el Estado, regiones que se configuraron a través de la historia al margen de los procesos de desarrollo y modernización.

Entre las principales causas del desplazamiento se destacan las amenazas, los señalamientos y las extorsiones por parte de grupos insurgentes como las FARC-EP, ELN ${ }^{4}$ y grupos paramilitares. Otra causa de desplazamiento que se menciona con frecuencia en los testimonios es la participación en programas estatales asociados

3 Corbetta (2003, p.327) define la observación participante como "una estrategia en la que el investigador se adentra: a) de forma directa; 6 ) durante un período de tiempo relativamente largo en un grupo social determinado; c) tomado en su ambiente natural; d) estableciendo una relación de interacción personal con sus miembros, y e) con el fin de describir sus acciones y de comprender, mediante un proceso de identificación, sus motivaciones".

4 Fuerzas Armadas Revolucionarias de Colombia-Ejército Popular (FARC-EP) y Ejército de Liberación nacional (ELN). 
al Plan Colombia ${ }^{5}$, fundamentados en la erradicación manual y/o aérea de cultivos de uso ilícito como la hoja de coca y amapola, aunque esta última situación no es reconocida por la legislación nacional como causa de desplazamiento forzado. La legislación reconoce en la Ley 387 de 1997 (CRC, 1997) las siguientes causas de desplazamiento:

Es desplazado toda persona que se ha visto forzada a migrar dentro del territorio nacional abandonando su localidad de residencia o actividades económicas habituales, porque su vida, su integridad física, su seguridad o libertad personales han sido vulneradas o se encuentran directamente amenazadas, con ocasión de cualquiera de las siguientes situaciones: Conflicto armado interno, disturbios y tensiones interiores, violencia generalizada, violaciones masivas de los derechos humanos, infracciones al derecho internacional humanitario $u$ otras circunstancias emanadas de las situaciones anteriores que puedan alterar o alteren drásticamente el orden público.

Establecerse en la ciudad de Ipiales significó para la población desplazada una segunda oportunidad de vida que involucró procesos de integración, inserción y construcción de nuevos sentidos y significados sobre su vida y sobre la vida de sus familiares. Estos procesos son mediados por la urgencia de sobrevivir en un mundo que es ajeno para ellos, donde se ven obligados a entrar en la dinámica de la competencia económica y social con los residentes de Ipiales y con otros migrantes.

La inserción laboral es la posibilidad que tiene la población para acceder a una oportunidad de trabajo formal o informal con una remuneración que le permita solventar algunas de las necesidades fundamentales como alimentación y vivienda, en una ciudad intermedia como la ciudad de Ipiales. La inserción laboral hace parte de los procesos de inserción social que la población en situación de desplazamiento experimenta al llegar a Ipiales, y se relaciona con lo que Lefebvre (1978) denominó "el derecho a la ciudad". Estos procesos de inserción implican que esta población pueda influir y participar dentro del tejido social de la ciudad para mejorar sus condiciones de vida y contribuir con el mejoramiento de la calidad de vida de la comunidad; asimismo, significa el disfrute y goce de derechos sociales y oportunidades vitales fundamentales, oportunidades y derechos que para esta población se ven limitados por su condición de desplazados, por las escasas oportunidades de empleo en los

Plan Colombia es un acuerdo bilateral constituido entre los gobiernos de Colombia y Estados Unidos. Se concibió en 1999 durante las administraciones del presidente colombiano Andrés Pastrana Arango y el estadounidense Bill Clinton con los objetivos específicos de generar una revitalización social y económica, terminar el conflicto armado en Colombia y crear una estrategia antinarcótica. 
lugares de llegada y por el estado de inconstitucionalidad de leyes y normas que se han formulado para la protección y defensa de sus derechos ${ }^{6}$.

El proceso de inserción social y laboral es aún más difícil cuando existe algún nivel de oposición en la población residente, como lo menciona Portes (2001, p. 117):

[...] oposición arraigada en varias razones: los trabajadores nativos y sus organizaciones comúnmente ven a los inmigrantes como competidores por empleo y sustento; las clases medias los ven como focos de contaminación y corrupción del medio físico, e incluso grupos de la élite que comúnmente emplean inmigrantes en sus empresas y hogares, se vuelven contra ellos cuando su creciente número empieza a indicar una amenaza política.

Es dentro de este ambiente de exclusión y oposición descrito por Portes (2001), donde la población desplazada llega a enfrentar un nuevo ciclo en sus vidas.

Para la mayoría de la población en situación de desplazamiento, el panorama al llegar a la ciudad de Ipiales no es muy alentador. Si en principio, les fue difícil encontrar un lugar donde vivir, es mucho más compleja la búsqueda de oportunidades laborales que les permita afrontar sus necesidades más inmediatas, desarrollar sus capacidades y potencialidades, y les favorezca los procesos personales de identificación y autoafirmación dentro del contexto urbano que para algunos es nuevo.

El campo laboral urbano es un juego de competencias donde gana quien mejor se desempeñe o quien más influencia tenga, y en la condición de desplazamiento la competencia se hace más difícil; como lo mencionan Ibáñez y Velásquez (2008) este proceso implica la destrucción de los escenarios productivos de la población rural y la pérdida de activos fijos, sucesos que tienen fuerte impacto económico tanto en las regiones que expulsan como en las regiones receptoras de población desplazada.

En este contexto, el presente escrito se organiza en cuatro apartados: en el primero se desarrolla la descripción contextual del mundo laboral dentro de la ciudad de Ipiales; en el segundo se aborda el trabajo informal como alternativa laboral. Dentro de este gran tema se desarrollan tres subtemas: el primero se asocia con la primera experiencia; el segundo trata de las experiencias laborales de las mujeres, y el tercero describe las experiencias laborales de los hombres; en tercer lugar, se presenta una lectura del papel de las redes sociales en estos procesos de inserción laboral, y por último se plantean las reflexiones finales.

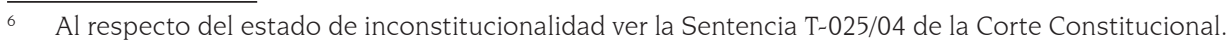




\section{LA CIUDAD FRONTERA Y EL CONTEXTO LABORAL}

La ciudad de Ipiales, por su ubicación fronteriza en el suroccidente colombiano, es paso obligado hacia el interior del país y hacia el vecino país del Ecuador. En tanto ventana abierta a los países del cono sur, la ciudad tiene dinámicas sociales y económicas particulares, como el crecimiento y alta movilidad poblacional, la oferta y prestación de servicios y el desarrollo de actividades económicas y comerciales del sector formal e informal a pequeña y/o a gran escala. A pesar de estas características y de su ubicación, esta ciudad brinda escasas oportunidades de empleo tanto para población residente como para los migrantes. Según percepción de la población desplazada "en esta ciudad es difícil encontrar trabajo. Nosotros venimos a buscar trabajo, pero acá no hay trabajo para los que son de aquí, mucho menos para desconocidos"7.

La población desplazada que llega a Ipiales ha tenido que buscar posibilidades laborales en diferentes lugares, pero las oportunidades son escasas o se les niegan debido a su condición de desplazamiento. Una de las causas ligadas a las escasas fuentes de empleo en Ipiales es la dependencia de las dinámicas económicas ecuatorianas sujetas al sistema cambiario, a las restricciones y tratados comerciales entre los dos países, y a su condición como ciudad periférica aislada de los centros hegemónicos, con escaso desarrollo industrial, científico y tecnológico.

Las principales fuentes de empleo de la región fronteriza de Ipiales son, en primer lugar, actividades relacionadas con el sector agropecuario y comercial, y en segundo lugar, actividades del sector micro-empresarial y turístico. La producción agrícola y pecuaria es de carácter minifundista; se desarrolla en pequeñas parcelas y está dirigida a mercados regionales, nacionales y un porcentaje menor para el consumo familiar, con bajo nivel de competitividad en relación con mercados de la región norte del Ecuador y de ciudades del interior de Colombia, como Pasto, Cali, Bogotá y Medellín. El cultivo de papa y la producción de leche son las actividades más predominantes y la fuente de la dinámica económica de la región. Esta producción cuenta con una escasa capacidad tecnológica de almacenamiento de productos perecederos y con un Centro de Acopio y Abasto de papa, con capacidad para 1646 toneladas. La mayoría de estas actividades se desarrollan con mano de obra familiar y de la región.

El sector comercial de Ipiales es muy inestable. El auge o decadencia del sector depende de las tasas de cambio que se presentan en el vecino país del Ecuador. Según el Compendio estadístico del movimiento empresarial de la CCI (2010), este municipio es el motor de desarrollo de la zona sur fronteriza y, por lo tanto, concentra el comercio

Síntesis general de las opiniones de los entrevistados en el trabajo de campo del estudio. 
de la región con 2738 establecimientos comerciales activos, que corresponden al $46 \%$ del total de establecimientos ubicados en los municipios colombianos ubicados en la frontera ${ }^{8}$. En el mismo estudio se evidencia que el sector más relevante de esta zona es el comercio en diferentes escalas, que representa $53.67 \%$ de la actividad económica del municipio, seguido por el transporte de carga y pasajeros, el almacenamiento de productos y las comunicaciones. Como esta información lo indica y autores como Grimson (2003, p. 89) lo argumentan, "el comercio y las otras actividades relacionadas, como el transporte, configuran la historia de las identidades y alteridades con consecuencias políticas en las regiones de frontera".

Otro dato interesante en relación con el sector comercial de Ipiales es que el 60 $\%$ de los locales comerciales cuentan con un registro mercantil y requisitos legales para su funcionamiento (CCI, 2010). En este sentido se entiende que el $40 \%$ de los locales comerciales no está registrado y funciona de manera informal, para evadir impuestos y trámites legales exigidos por las entidades competentes como Cámara de Comercio y Dirección de Impuestos y Aduanas Nacionales. Esta modalidad de comercio informal está relacionada con actividades de contrabando, el cual se presenta entre otras razones debido a las escasas oportunidades laborales, la falta de legalización de acuerdos y normas comerciales con el Ecuador y los altos costos de transporte de mercancías que provienen del interior de Colombia. En este mismo estudio se evidencia que si bien es cierto existe una Ley de Fronteras, Ley 191 de 1995 (CRC, 1995), la cual tiene por objeto establecer un régimen especial para las Zonas de Frontera, con el fin de promover y facilitar su desarrollo económico, social, científico, tecnológico y cultural, en el municipio de Ipiales esta ley no se aplica de manera eficiente, entre otras causas debido a la falta de interés por parte de los gobiernos municipales, así como también a la incidencia del conflicto armado y la inseguridad social presente en Colombia.

El mayor porcentaje de establecimientos comerciales informales se encuentran ubicados en la plaza de mercado o galería central, donde se ofrecen productos de contrabando, traídos de manera ilegal del Ecuador, como ropa, víveres y abarrotes, debido a que se pueden comercializar a menor costo. Otros productos que se comercializan de manera ilegal en la frontera colombo ecuatoriana son la gasolina y el gas. En relación con la comercialización ilegal de gasolina Gustín (2011) informa "que a esta actividad ilegal se dedican más de mil familias de los municipios fronterizos de Ipiales, Cumbal, Aldana, Carlosama, Pupiales, entre otros".

De la misma manera, Prado (2011) informa que la Dirección de la Regional Norte

8 Los municipios colombianos de frontera: Aldana, Contadero, Córdoba, Cuaspud, Cumbal, Guachucal, Gualmatan, Iles, Ipiales, Potosí, Puerres, Pupiales y Ricaurte. Y por Ecuador las provincias del Carchi, Esmeraldas y Sucumbíos. 
de Hidrocarburos de Ecuador pone de manifiesto que los comerciantes utilizan 18 pasos ilegales ubicados en el cordón fronterizo, en los cuales a través de motocicletas, bicicletas y caballos, transportan el combustible desde ciudades como Tulcán a Ipiales, y de allí al resto de municipios de la antigua provincia de Obando. Esta actividad ilegal se ha convertido en una fuente de empleo tanto para las personas residentes de la ciudad de Ipiales, como también para personas de otros municipios fronterizos de Nariño y de la población migrante que llega al sector fronterizo.

Un sector relacionado con el comercio es el de transporte tanto de mercancías como de personas, el cual se encuentra organizado en diferentes empresas que prestan el servicio local, regional y nacional. Taxis colectivos, taxis de servicio público, microbuses y busetas prestan el servicio de transporte urbano. Empresas de camiones y camperos prestan el servicio de transporte mixto de carga y pasajeros, y en algunos casos vehículos tipo taxi ofrecen el transporte hacia las veredas y municipios cercanos. Con respecto al transporte de carga, esta es una de las actividades más complejas en cuanto a su estructura y organización interna debido a la necesidad de movilización de grandes volúmenes de productos de intercambio regional e internacional hacia el norte y sur del Continente. Este sector se ha convertido en otra fuente de empleo para las personas en situación de desplazamiento.

Finalmente, en cuanto a fuentes de empleo también se destacan los sectores financiero, industrial e institucional. La actividad financiera estimula el movimiento comercial resultante de la situación cambiaria de la frontera; sirve de apoyo a la dinámica económica de la región, y en particular de la ciudad de Ipiales. El sector industrial no es muy dinámico debido a factores asociados a las políticas nacionales y a la falta de aprovechamiento de la integración binacional. En el POT (2007) se encuentran registradas algunas industrias de transformación, de tipo liviano, dentro de las cuales se destacan las productoras de harina de trigo, tostadoras de café y otros establecimientos industriales que utilizan insumos primarios extraídos de la región, como en el caso de los aserraderos de madera, las microempresas dedicadas a actividades de carpintería, tejidos en lana, ebanistería, confecciones, elaboración de calzado, cerámicas, artesanías, entre otras de menor envergadura. Estas pequeñas empresas utilizan como mano de obra, en promedio, tres personas, y se destacan de manera importante como unidades generadoras de empleo.

El sector institucional cobra importancia en razón del carácter fronterizo de la ciudad. En este sentido se cuenta con la presencia de organismos estatales que cumplen diversas funciones de relaciones internacionales de nivel comercial, aduanero, administrativo, agropecuario, de seguridad, y ONG nacionales y de cooperación internacional. La presencia de estas últimas responde a la dinámica que 
ha tomado el conflicto armado en la zona de frontera durante la última década y se han enfocado en el impulso de procesos de generación de ingresos.

Otro sector que se considera fuente generadora de empleo, aunque en menor magnitud, es el turismo, un sector escasamente explotado en la ciudad, pero que influye en la economía local y regional. El principal sitio turístico dentro del municipio de Ipiales es el Santuario de la Virgen de la Lajas, sitio de culto católico y veneración de la Virgen, donde cada año y día a día, llegan turistas de diferentes partes de Colombia y de Ecuador, así como de otros lugares de América. En este mismo orden de ideas, la ciudad se considera sitio turístico durante la época de fin y principio de año debido a la celebración del carnaval de negros y blancos.

Para finalizar, es importante mostrar algunas cifras que revelan la importancia de cada uno de los sectores mencionados como fuentes generadores de empleo en la ciudad de Ipiales. La situación que se presenta se evidencia en el siguiente cuadro.

Cuadro 1. Puestos de trabajo generados según actividad económica

\begin{tabular}{|l|c|c|}
\hline Actividad Económica & No de empleos generados & Participación \% \\
\hline Comercio & 147 & 41,4 \\
\hline Servicios & 86 & 24,2 \\
\hline Transporte & 79 & 22,3 \\
\hline Construcción & 27 & 7,6 \\
\hline Industria & 12 & 3,4 \\
\hline Agricultura & 4 & 1,1 \\
\hline Total Empleos & 355 & 100 \\
\hline
\end{tabular}

Fuente: POT (2007, p. 27)

Las 50 principales empresas de Ipiales generan 355 empleos directos, de los cuales el 41,4\% son aportados por el sector comercio, el 24,2 \% por servicios; el $22,3 \%$ por transporte, el 7,6 \% por la construcción, el 3,4 \% por la industria y el 1,1 $\%$ por el sector agrícola. Cabe destacar que los puestos de trabajo relacionados en el cuadro son permanentes; no se contabilizan los originados por actividades como la construcción, que absorbe una cantidad importante de mano de obra en desarrollo de sus labores y de las cuales no se tiene información en los registros consultados, pero que sin duda es una de las ramas que más mano de obra ocupa. 
El anterior contexto muestra que si bien es cierto que las principales actividades económicas de la región son la agricultura y la ganadería, estos son los sectores que menor número de empleos generan en el municipio y, en particular, para los habitantes de la zona urbana, situación que se explica en razón del carácter minifundista y familiar de la producción. Se deduce, entonces, que el sector que mayor número de empleos genera en el municipio en general y en la ciudad en particular es el comercio, tanto formal como informal.

Ahora bien, es importante destacar que en esta región fronteriza se encuentran y relacionan comunidades multiétnicas y pluriculturales como indígenas Pastos, campesinos, mestizos, afrodescendientes, población urbana, migrantes de diferentes regiones del país, migrantes ecuatorianos y de otros países de Suramérica. Este contexto, sumado a los efectos del conflicto armado y el desplazamiento forzado, le imprime características particulares a las dinámicas económicas urbanas y nuevos desafíos para el desarrollo económico y social de la región.

A continuación se analiza la situación y las estrategias de inserción laboral de la población en situación de desplazamiento forzado en la ciudad de Ipiales, situación que evidencia precariedad y dificultades como las escasas oportunidades de empleo dentro de esta ciudad y las condiciones de llegada de esta población.

\section{EL TRABAJO INFORMAL, LA ALTERNATIVA LABORAL: “EL REBUSQUE”9}

Para la población desplazada la primera experiencia de trabajo dentro de la ciudad de Ipiales se encuentra relacionada con la economía informal. En este sentido se realiza un acercamiento teórico y conceptual sobre los enfoques interpretativos de la economía informal, a partir de los cuales se analizan las diferentes experiencias laborales del desplazado al llegar a Ipiales.

El DANE (2004, p. 5) informa que

[...] la informalidad y su rápida expansión es un fenómeno que se ha convertido en una característica estructural de la economía colombiana. Este tipo de economía carece de las garantías mínimas para el bienestar del trabajador como protección social, ingreso adecuado y estabilidad convirtiéndolo en un campo determinante de desigualdad social.

Este es el panorama laboral que vive el mayor porcentaje de población en situación de desplazamiento en la ciudad de Ipiales, así como en otras regiones del país.

\footnotetext{
9 "Rebusque" es la palabra que los entrevistados utilizan para referirse a la búsqueda de empleo por primera vez en la ciudad de Ipiales.
} 
AlSayyad (2004, p. 10) analiza lo planteado por la OIT donde se destacan las principales características de las actividades informales:

La OIT en un informe de 1972, señaló que el sector informal se refiere principalmente a las actividades de "pequeños comerciantes, vendedores ambulantes, lustrabotas y otros grupos" subempleados en las calles de las grandes ciudades, e incluye una amplia gama de los asalariados autónomos, tanto hombres como mujeres. "El informe argumenta que estas actividades informales representan una forma de hacer las cosas caracterizada por: a) la facilidad de entrada, b) la dependencia de los recursos indígenas, c) propiedad familiar de las empresas; d) operaciones a pequeña escala, e) mano de obra y adaptación tecnológica; f) las competencias son adquiridas fuera del sistema escolar formal, y g) los mercados no regulados y competitivos.

Las características de las actividades informales desatacadas por la OIT mantienen vigencia en la actualidad, y más cuando estas actividades hacen parte de los nuevos procesos de urbanización, los cuales se encuentran relacionados con procesos migratorios y en el caso de la ciudad de Ipiales y otras ciudades de Colombia, con procesos de desplazamiento forzado. Hombres y mujeres en las calles de las ciudades buscando trabajo día a día para poder sobrevivir y suplir sus necesidades más inmediatas, enfrentados a situaciones de discriminación, competencia con la economía formal, lucha por espacios como la calle y las plazas de mercado.

Según Rakowski (1994) la visión de la OIT sobre el trabajo informal se enmarca en una visión estructuralista según la cual existe una clara división entre lo formal y lo informal, donde la informalidad tiene unas características específicas como el fácil acceso, la pequeña escala y una forma de hacer las cosas. Pero, por otro lado, reconoce la informalidad como una condición de trabajo no declarado o no contractual que carece de beneficios, paga menos del salario mínimo y los trabajadores no tienen ningún tipo de protección, incluye estrategias de fraude fiscal y no pago de impuestos.

En países como Colombia, el enfoque estructuralista permite comprender el fenómeno como factor asociado a las condiciones de amplias desigualdades sociales generadas por el sistema capitalista en América Latina. Colombia es un país con amplias desigualdades sociales, y altos índices de pobreza. Para el año 2010, según el periódico El Colombiano (2011), este índice fue de $40.2 \%{ }^{10}$, y según el DNP (2011, p. 1) "el índice de pobreza multidimensional" en la zona urbana registra una incidencia de pobreza

10 Este índice se evalúa en razón de la nueva metodología implementada por el DNP y donde se tienen en cuenta principalmente los ingresos y la pobreza monetaria

1 El índice de pobreza multidimensional (IPM), desarrollado por el Oxford Poverty \& Human Development Initiative (OPHI), es un indicador que refleja el grado de privación de las personas en un conjunto de dimensiones. El IPM está conformada por cinco dimensiones y quince variables. 
multidimensional de 27 \% en el 2008 y en la zona rural la incidencia fue de 61 \% más de dos veces del porcentaje de personas pobres en la zona urbana".

Por otro lado, el enfoque legalista, que según Rakowski (1994) se centra en perspectivas neoliberales y legales burocráticas, donde la diferencia entre el trabajo formal e informal radica en las restricciones institucionales que hacen que la informalidad se convierta en una estrategia económica racional, también proporciona elementos para el análisis de las normas y restricciones que se han institucionalizado en Colombia, con el fin de regular las diferentes modalidades de trabajo, actividades que se realizan por parte de entidades como las Cámaras de Comercio y la Dirección de Impuestos y Aduanas Nacionales. En este último enfoque vale la pena resaltar los aportes de De Soto (2007) quien atribuye la informalidad a excesiva normativa del Estado y no a la dinámica del mercado de trabajo. En este sentido AlSayyad (2004, p. 13) citando a Rakowski (1994) se refiere a la informalidad como una manera de romper con las barreras legalistas. Asimismo, Portes, Castells y Benton (1989) aclaran que la diferencia entre la economía formal e informal no guarda relación con las características del producto final si no con la forma en que este es producido e intercambiado. Y Elyachar (2005, p. 11) citando a Portes y Haller (2004) menciona que "prácticas sociales, en este caso la informalidad, que había sido un recurso local para la supervivencia, y había sido visto a menudo como un obstáculo al desarrollo económico, se ve ahora en forma de capital social que permite la reproducción de mercados globales".

Desde las anteriores perspectivas tanto el enfoque estructuralista como el legalista y la visión de la informalidad como potencial para el desarrollo de mercados mundiales, contribuyen al análisis del trabajo informal, donde la migración ruralurbana actúa como catalizador del trabajo informal, como ocurre en Colombia con los procesos de migración económica y desplazamiento forzado. Sin embargo, el trabajo informal en el contexto del desplazamiento forzado, más que ser un asunto de legalidad es un asunto de carácter estructural, ya que esta población encuentra en el trabajo informal una forma de vida que le permite solventar el día a día y de manera rápida sus principales necesidades. Esta posición no desconoce que dentro de esta ciudad existen casos de informalidad que no están sujetos al contexto del desplazamiento forzado, para los cuales se hace necesario otro tipo de análisis.

2.1 La primera experiencia. Ibáñez y Moya (2007, p. 51) resaltan "el perfil básicamente agrícola de las cabezas de familia, producto de la procedencia rural de la población desplazada, supone grandes obstáculos para su inserción en el mercado laboral urbano". Esta situación influye en las posibilidades laborales a las cuales puede aspirar la población desplazada. Bajo este contexto, para esta población las primeras experiencias de trabajo están llenas de dificultades. La baja escolaridad de estas personas las pone 
por fuera de la competencia del mercado laboral formal. La escasa experiencia en los sectores comerciales y de servicios, la baja remuneración en empleos no calificados, la desconfianza por parte de la población residente donde llegan a buscar trabajo, y, en general, el desconocimiento de las dinámicas de Ipiales, son las principales dificultades que afronta el "desplazado" al establecerse en el lugar de llegada. La población entrevistada manifiesta "Aquí uno se sentía los primeros días mal, porque nadie lo conocía, sin trabajo, sin nada, usted ya sabe cómo es cuando se llega por primera vez, todo mundo desconfía de uno".

La búsqueda de trabajo o "rebusque", como ellos lo llaman, se realizaba en las plazas de mercado donde, "se iba a lo seguro" ya que, si no era posible encontrar qué hacer para ganarse el día, así sea del basurero se recogía cualquier producto que podía servir para llevar a la casa. Así lo manifiesta Flavio (2010): "Mientras tanto yo me iba a la galería a rebuscar, a ver que se caía por ahí, una papita, un platanito, para poder colaborar allá. Cogí un costal y me fui al mercado, entonces, me fui bien cambiadito y llegue allá y un señor de un carrito estaba cargando unos bultos y me ofrecí a ayudarlo...".

Contar con la colaboración de amigos y familiares favorece en alguna medida el poder encontrar una primera oportunidad laboral. Asimismo, la experiencia en un lugar previo de residencia, donde se establecieron algunas relaciones laborales y experiencias exitosas y no exitosas, se convierte en referencia para la inserción laboral. Así es el caso de una familia desplazada de Puerto Caicedo en el departamento del Putumayo quienes buscaron una oportunidad en la ciudad de Mocoa, en la plaza de mercado. Sin embargo, los resultados no fueron satisfactorios, ya que no encontraron ayuda por parte de quienes administraban el lugar, situación que los motiva a solicitar colaboración a familiares que trabajaban en Nariño en la zona de frontera y en la Costa Pacífica. Es así como llegan a la ciudad de Ipiales y logran establecer una forma de vida y de trabajo, con la ilusión de poder encontrar una actividad similar a la que tenían en su lugar de previa residencia. Alex (2010) comenta:

Entonces la idea era que yo trajera mi bultico para yo vender raleado y poder hacer algo más. Y no, la administración del mercado de Mocoa, a nosotros los desplazados nos sacaba, que no le hagamos competencia a la gente que ya estaba ahí hace mucho tiempo. Era una discusión grande, en la cual yo miré que estaba difícil mantenerme allí...Yo venía con la ilusión de que por acá en Ipiales iba a haber una cooperativa para meter ese carro, pero ya por acá había sido más civilizado esto.

En las primeras experiencias laborales de la población en situación de desplazamiento se evidencia la lucha por la competencia, discriminación y exclusión por parte de residentes donde llegan a trabajar, lo que conlleva a la estigmatización de estas personas. Goffman (2006, p. 13) argumenta que "el estigma opera simplificando a las personas a partir de un atributo profundamente desacreditador, proponiendo un lenguaje 
de relaciones y no de atributos. Un atributo que estigmatiza a quien lo porta puede confirmar su normalidad o anormalidad". En este sentido, la estigmatización se convierte en otro obstáculo que el desplazado afronta a la hora de buscar una oportunidad laboral.

Las primeras experiencias de trabajo dejaron grandes huellas que recuerdan con gran nostalgia por las dificultades que tuvieron que padecer y debido a los malos tratos y a la discriminación de los cuales fueron víctimas. Así lo relata Patricia (2010):

Por lo que me ha tocado duro en la casa de familia que le cuento. Lo difícil del trabajo. Pues allá donde yo trabajaba, me daba yo cuenta, que uno haciendo las cosas para terminar más rápido... no, pero eso más trabajo le hacían hacer a uno. Esos trabajos lo hacen arrepentir y llorar amargamente.

Estas situaciones los marcan y los llenan de nostalgia con los recuerdos de una vida pasada idealizada.

A pesar de las malas experiencias, siempre tienen la ilusión de poder encontrar condiciones favorables en otros lugares. Sin embargo, la situación no cambia, ya que el contexto, las reglas de juego y las competencias son diferentes a los que ellos estaban acostumbrados. Como lo mencionan, al llegar a Ipiales "todo parecía más civilizado", situación que impidió cristalizar las ilusiones de algunas de las familias. Esta fue una etapa que implicó grandes retos para la población: conocer el contexto, buscar estrategias para generar empatía con los residentes o posibles empleadores, recurrir a la ayuda de los familiares, acudir a lugares más populares y más frecuentados como la plazas de mercado, con el fin de conocer gente y establecer relaciones que les posibilitaran de alguna manera su inserción en el mundo laboral y social.

Las experiencias laborales de la población desplazada se asocian con empleos de servicio doméstico, lavado de ropa, ventas ambulantes, en el caso de las mujeres, y actividades agropecuarias, en el sector de transportes, en talleres mecánicos, en parqueaderos, en el caso de los hombres.

2.2 Oportunidades laborales para las mujeres: en primer lugar, es importante mencionar que el contexto del desplazamiento forzado, además de conllevar el proceso de reconfiguración territorial, conlleva también una reconfiguración en los roles que tradicionalmente desempeñan hombres y mujeres (Mertens, 2004). En los procesos de inserción laboral se visualiza esta situación, cuando al llegar a la ciudad les es mucho más fácil conseguir trabajo a las mujeres que a los hombres.

Bajo el contexto de la informalidad y de las escasas fuentes de empleo en Ipiales, las casas de familia y los oficios domésticos se convierten en las principales 
opciones de trabajo para las mujeres en situación de desplazamiento. Esta es una oportunidad laboral con baja remuneración pero que, al menos, les garantizaría un mínimo ingreso para poder sostener a su familia, en tanto se encuentra una mejor oportunidad. Martha (2010) menciona "Yo lavaba ropita, busqué trabajito para lo del arriendo... Yo no trabajaba, o sea, solo en oficios varios, a veces haciendo aseo de casas, jabonar, esas cositas...".

Los oficios que por lo general se les encarga a las mujeres van desde el lavado de ropa, el aseo de la casa, la preparación de los alimentos, hasta la crianza de los niños. Debido a la cantidad de trabajo y la diversidad de actividades que se les encarga ellas sienten que han sido víctimas de explotación laboral. Las largas jornadas de trabajo, docenas de ropa por lavar, personas que atender, correr de un lado a otro, hicieron parte de las experiencias laborales de estas mujeres; Patricia (2010) comenta: "Uno, esté enferma o esté alentada, tener que aplanchar, jabonar, encerar, virutear, trapiar y corre. Que un desayuno, dice la tal persona, que el otro dice, que no se qué. Es que allá yo pues la miraba durísimo".

Estas experiencias de explotación laboral configuran las asimetrías múltiples que tienen que superar: la asimetría de ser víctimas del desplazamiento forzado y la explotación laboral en los sectores donde llegan a habitar.

Además de trabajos domésticos, se encuentra que parte de la población femenina ha buscado oportunidades laborales en otros sectores del trabajo informal, donde ponen en práctica sus habilidades manuales, su carisma, la iniciativa y creatividad para establecer sus pequeños negocios de manera independiente. Entre los trabajos más comunes se encontraron: ventas ambulantes de comidas rápidas y refrigerios, artesanías, venta de minutos, venta de frutas y verduras, cultivos de arveja, ventas por catálogo y como lideresas de la población en situación de desplazamiento, a través de asociaciones.

Las ventas ambulantes de comidas rápidas y refrigerios se desarrollan en la calle, en las plazas de mercado, en los almacenes, en parqueaderos, en instituciones como la Alcaldía Municipal, donde encuentran la clientela y pueden vender sus productos. Así lo relata Esperanza (2010): "ahora tengo este carrito y me voy a vender café a los talleres y parqueaderos, salgo a las 10 de la mañana y regreso a las tres". Los horarios de trabajo se ajustan a las dinámicas de los lugares donde suelen vender sus productos y al tiempo requerido para la preparación de los mismos.

La preparación de los alimentos implica que estas mujeres comiencen su jornada desde las cuatro de la mañana, la venta de los productos comienza a las siete y ocho de la mañana y termina entre las tres y cuatro de la tarde horario durante el cual encuentran mayor número de clientes. Esperanza (2010) 
continua relatando "... ahorita estoy vendiendo papa con maní y dulce, dulce de calabaza, dulce de mango, dulce de papayuela, la fruta que encuentre más barata... y los distribuyo en la calle...comienzo a las cuatro de la mañana y estoy terminando a las cuatro de la tarde". Estas jornadas de trabajo son impuestas por ellas mismas, en razón de lo que les exigen las dinámicas de la clientela hacia la cual se dirigen los productos.

Otro grupo de mujeres se dedican a las artesanías. Las habilidades manuales les han permitido encontrar en sus propias creaciones, alternativas para percibir ingresos. Para algunas, esta labor se convierte en su principal fuente de ingresos; para otras, son aportes que se suman a los ingresos de la familia. Carmen (2010) menciona:

A mí me gusta mucho estas cositas (muestra con la mano arreglos decorativos elaborados a mano que los tiene colgados sobre la pared)... yo no he hecho cursos, nada, simplemente mirando y he sacado así. Esta muñeca la miré en el supermercado y la saqué también. Eso es para 15 años, matrimonio, bautizos... Ya hay varias señoras que me dicen que yo decoro, decoración de bomba, de 15 años, todo eso. Sí señora aquí decoro, ese es mi oficio, digamos.

Para Carmen (2010) la decoración es su oficio a partir del cual logra percibir algunos ingresos con los cuales apoya a su esposo con los gastos del hogar. Este oficio lo desarrolla desde su casa y el horario lo combina con las labores del hogar, el cuidado y acompañamiento en los estudios de sus dos hijas. Lo difícil en este tipo de trabajos es que están sujetos a la demanda de los productos que estas mujeres puedan ofertar y no cuentan con un ingreso diario seguro.

Otra oportunidad laboral para las mujeres es la venta de minutos y la venta de diferentes mercancías por catálogo, como productos de belleza, medicamentos naturales y ropa. Se destaca de estas mujeres la iniciativa y el coraje con el cual han enfrentado la situación de desplazamiento, las escasas posibilidades laborales y las bajas remuneraciones. Estas actividades se han tenido que combinar con otras posibilidades de ingresos como cuidar niños, lavar ropa, cosechar arveja, entre otros trabajos casuales que resultan. Carmelina (2010) cuenta:

[...] tenemos unos minuticos, que estamos vendiendo y así no la rebuscamos, y de todas maneras, con lo que nos da el jabonado y eso, a veces nos toca duro. Hoy iba a coger alverja, pero por la niña no pude... por otro lado, la señora me paga cincuenta mil pesos (\$50.000) mensuales por cuidarle el niño, pero desde las 4 de la tarde hasta las 8 de la noche, me toca irlo a recoger al hogar y luego llevárselo a la casa de la señora que vive por la plaza de mercado. Por mi hija es que no puedo trabajar por fuera.

En la venta por catálogos no se cuenta con un salario fijo, este depende de la 
cantidad de pedidos y de ventas reales que se hagan. A pesar de que el tiempo es manejado por cada una de ellas, este tiempo invertido no siempre garantiza que sea recompensado. En palabras de Perla (2010) "Ahorita con las ventas por catálogo, no me ha quedado tiempo es que hay tiempos temporadas más buenas, temporadas malas, es muy difícil. Aquí pues la gente prefiere irse al Ecuador hay cosas que salen bien acá y cosas que salen bien por allá".

Esta actividad de venta por catálogo en Ipiales se vuelve más difícil debido a la competencia comercial, ya que tienen que competir con el comercio dentro de la ciudad, y con productos y mercancías que llegan del vecino país del Ecuador, las cuales como ya se mencionó, están sujetas a la variación del precio del dólar. Razón por la cual en el testimonio se manifiesta que existen temporadas buenas y temporadas malas, ya que cuando el precio del dólar baja, las mercancías que se traen del Ecuador son más económicas que las que se encuentran en la ciudad de Ipiales.

Otro grupo de mujeres han recurrido a préstamos por parte de entidades financieras, y a pesar de que algunas de estas entidades le cierran las puertas a esta población por su condición de desplazamiento, ellas se arriesgan a gestionar estas posibilidades con el fin de establecer su propio negocio, como lo cuenta Patricia (2010):

[...] pero ahora como me dan un préstamo en Mundo Mujer. Antes, lo bueno que allá no me preguntaron de dónde era ni nada. Sino que yo dije que quería trabajar vendiendo frutas. Entonces dijeron, que dónde era el puesto. Vinieron, me lo vieron aquí y bueno me dijeron: "con mucho gusto le prestamos quinientos mil pesos (\$500.000)". Entonces yo le digo a él vea con quinientos mil pesos pudimos surtir el negocio, no, y así hemos salido.

La Fundación Mundo Mujer' ${ }^{2}$, una entidad financiera cuyo principal objetivo es el fortalecimiento de microempresas familiares lideradas por mujeres cabeza de familia, apoya con préstamos a algunas de estas mujeres desplazadas, permitiéndoles establecer pequeños negocios de manera independiente, generar ingresos, apoyar a la familia, pero sobretodo, para ellas ha significado el poder liberarse de la tensión y la explotación de la cual han sido víctimas en anteriores experiencias.

Otras formas de trabajo para las mujeres son las organizaciones tanto de trabajo productivo como de gestión, liderazgo y apoyo a la población en situación de desplazamiento. Salcedo (2006, p. 223) al respecto menciona: "la tragedia de haber

12 La Fundación Mundo Mujer, es una organización financiera sin fines de lucro, certificada por el ICONTEC e IQNET en el Sistema de Gestión de Calidad, afiliada a la Red del Women's World Banking y a la Red de Microfinanzas (RMF) - FOMIN. El objetivo de la Fundación es mejorar la calidad de vida de la mujer trabajadora de escasos recursos y de su familia, mediante el acceso fácil y oportuno al crédito y otros servicios. 
desaparecido, la muerte, o el secuestro de seres queridos ha llevado a muchas mujeres a organizarse con el propósito de desarticular la lógica de la guerra y para favorecer la vida". Como el autor lo menciona las mujeres víctimas del desplazamiento, en su nueva situación, buscan alternativas para superar las consecuencias de la guerra y poder continuar con nuevas formas de vida, y las diferentes formas de organización se convierten en estrategias para lograr este objetivo.

Una asociación de modistería se constituyó a partir de capacitaciones impartidas por el SENA, el acompañamiento profesional y financiero por parte de las corporaciones Arco Iris y Acción Social. En principio esta asociación la conformaron treinta personas entre quienes se encontraban varias personas en situación de desplazamiento y población en situación de vulnerabilidad dentro de la ciudad. En la actualidad, la asociación está conformada por nueve personas, de las cuales dos se mantienen más activas. Lilia (2010) describe algunos detalles:

Después nos asociamos con Plinio y Gloria y otra compañera que se llama Mery, y nos dieron la máquina del proyecto, la otra plana. En eso, pasó que me llego la otra ayuda humanitaria, yo no me la gasté, inclusive así me quede sin el colchón, sin los platicos, yo volví y compre la otra máquina. O sea que las ayudas humanitarias que me ha dado Acción Social las tengo en las máquinas y con un contrato que hicimos de maletines para ACNUR, hicimos un contrato de faldas para los colegios, otro contrato para el Sena, de unos contratos que hemos hecho me hice esa (indica otra máquina), lo que me pertenecía a mi lo guarde y fui ahorrando y me metí en esa...

En el caso de las organizaciones es fundamental la gestión de contratos y solicitud de apoyo en diferentes entidades, así como también la inversión de las ayudas humanitarias de las cuales han sido beneficiarias.

El trabajo de fortalecimiento y apoyo a organizaciones y a población en situación de desplazamiento identifica a muchas de las mujeres desplazadas ubicadas en esta ciudad. Estas mujeres se han dedicado a la gestión de ayudas para ellas, sus familias y para otra población que comparte su misma situación. También han sido las gestoras de movilizaciones en defensa de sus derechos y en protesta por las atroces consecuencias del conflicto armado. Al respecto Martha (2010) cuenta su experiencia:

[...] yo he conseguido las cosas, como uno tiene capacitación y puede defenderse sí. Pero hay gente, definitivamente da pesar. Yo así, que así, aunque no sean familia, yo sería a un lado mendigar, a otro a acompañar a las señoras, pues que son madres de cabeza de familia y todo. Están con los niños enfermos, no les hacen caso. Ellas se enferman, les niegan una cosa, otra, yo les digo: "vengan, eso se hace así, vamos yo le ayudo". Yo he ayudado a hartísima gente. Todos dicen: "Doña ayúdeme" entonces yo corro para allá, para acá. 
Martha (2010) se distingue entre la población desplazada por su liderazgo y emprendimiento, y entre las instituciones, por la gestión diaria que ha realizado para beneficio propio y de la población que atraviesa su situación, en especial mujeres. En las instituciones la identifican como <la señora de las tutelas $>$.

Entre las mujeres que han desempeñado diferentes trabajos de manera independiente y por iniciativa propia, se percibe mayor entusiasmo y satisfacción que en aquellas que se encuentran vinculadas como empleadas domésticas y/o en oficios del hogar. En sus palabras se refleja el interés por salir adelante y por contar con una posibilidad laboral propia, a pesar de que no tienen un salario fijo y que se enfrentan al día a día sin una estabilidad económica asegurada.

2.3 Oportunidades laborales para los hombres. En contraste con las mujeres, la situación laboral de los hombres es más compleja, por cuanto para ellos ha sido más difícil la vinculación en un trabajo sea este formal o informal. Entre las razones que dificultan la consecución de empleo se encuentran, la desconfianza que genera un hombre desconocido entre la población residente, la escasa iniciativa y creatividad para emprender diferentes trabajos como lo hicieron las mujeres, el sentimiento de persecución y señalamiento del cual no han logrado desprenderse después de que fueron víctimas del desplazamiento y, como ya se ha mencionado, las escasas fuente de empleo dentro de la ciudad de Ipiales.

Los principales espacios laborales para los hombres se encuentran en el sector rural, en las empresas de transporte, en las plazas de mercado, y en los talleres mecánicos. Las experiencias previas en zonas rurales se convierten en factores determinantes en la vinculación laboral de este grupo de población. Como lo cuenta Flavio (2010): "Bueno, en la finca yo cuidaba ganado, a veces los vecinos decían: "vea ya hay estas papas para coger". Entonces yo me iba a coger papas. Cuidaba ganado. El señor tenía 25 cabezas de ganado y me pagaba por cuidárselas".

Algunos hombres y sus familias logran vincularse al sector agrícola y pecuario en la periferia de la ciudad, donde además de trabajo, tienen una vivienda donde habitar. Aunque las condiciones no eran las mejores, fue una oportunidad que les permitió sobrevivir. En otros casos el contar con la habilidad para conducir les permitió vincularse a un trabajo por un tiempo. Sin embargo, en ninguno de los dos sectores mencionados (agropecuario y transporte) las condiciones laborales eran, ni son las más adecuadas. Al igual que para las mujeres, las bajas remuneraciones, la explotación laboral, las largas y extenuantes jornadas de trabajo, son situaciones que esta población tiene que soportar. Lo más difícil en estos dos sectores laborales para los hombres es la inestabilidad; por un lado, quienes encuentran una oportu- 
nidad en el sector agropecuario dependen de las temporadas de siembra, cultivo y cosecha de productos como papa o arveja. Como lo relata Pablo (2010) "por ahí en oficios varios, en lo que haya que hacer. A veces me voy a cuidar chagra de arveja, cuando es temporada o a cosechar papas cuando hay".

En el sector de transporte los hombres se vinculan como ayudantes y/o choferes de carros de transporte público interurbano e intermunicipal. Así lo relata Rosa (2010) al referirse a su esposo: "Sí, pues a él los choferes que a veces tienen que hacer alguna vuelta, no los dueños, sino los choferes de la empresa, le pagan para que les hagan el turnito... él trabajaba llevando gente de la catorce a Rumichaca". La condición fronteriza de Ipiales, el comercio que se desarrolla con la ciudad de Tulcán en Ecuador y los bajos costos del combustible en el Ecuador, han favorecido al sector transportes, y lo han convertido en una importante fuente generadora de empleo, para la población.

Otro sector generador de empleo para los hombres es el de los talleres mecánicos, donde se desempeñan trabajando con metal y en labores asociadas a la mecánica automotriz. Para el desempeño en este trabajo es importante la experiencia previa y los conocimientos con los cuales se cuenta. Quienes no contaron con experiencia ni con conocimiento, tuvieron que aprender a utilizar las herramientas de trabajo, familiarizarse con las jornadas laborales, con las exigencias de los clientes y del jefe inmediato, lo que significó un proceso de aprendizaje y adaptación a este medio. Flavio (2010) describe su experiencia:

[...] de allí en el taller, por ahí por la Panamericana, en un taller de carrocerías me dieron la oportunidad de entrar a trabajar. Pues igual, uno en el campo el trabajo es diferente, algunas iniciativas sí, porque pues ya había manejado martillo, pero acá ya tocaba todo a la perfección pues. Armar carrocerías, pues me tocó muy duro, porque pues no conocía eso, entonces tocaba raspar latas, todo eso de llantas, trailes que hacían, las carrocerías, todo el día lijando, eso me dio duro, pero pues tuve arto trabajo.

Las plazas de mercado, las fábricas de ladrillo son espacios donde se encontró una posibilidad laboral, con bajas remuneraciones, con características de informalidad y que exigen un trabajo físico desgastante. Leonor (2010) nos comenta acerca de sus hijos: "Antes los muchachos trabajaban haciendo ladrillo, porque ellos han trabajado en lo que les ha salido. De cotero, lavando, cosechando papa, últimamente cortar palo y secar para vender, ladrillo...".

Al igual que en el caso de las mujeres, los hombres que se valen de sus conocimientos en normas y leyes relacionadas con población en situación de desplazamiento y gracias a su liderazgo y gestión, logran vincularse de manera temporal en instituciones como la Alcaldía Municipal, donde se desempeñan como asesores 
en asuntos de gestión, ayuda humanitaria, trámite de documentos, derechos de petición, tutelas y capacitaciones con la población desplazada. Así lo narra Alex (2010): "Entonces yo les colaboro a la población desplazada a hacer papeles, para meter derechos de petición y así a cualquier cosa, porque como yo sí me defiendo en eso. Conozco un poquito de derecho. Uno les ayuda y no les cobra comisión, si no lo que ellos le quieran dar".

Sin embargo, el desempeño en este tipo de labores casi nunca tiene una remuneración fija. Se realiza por iniciativa propia y sobre todo por parte de aquellas personas que han tenido mayor experiencia y quienes se han destacado por su liderazgo y un conocimiento mínimo de la política pública y legislación sobre atención a población desplazada, ellos solo esperan recibir algún tipo de bonificación a voluntad de la persona a quien le colaboran.

\section{REDES SOCIALES Y FAMILIARES}

Las redes sociales se forman gracias a las relaciones que se establecen entre personas que comparten ciertas condiciones o situaciones, como en este caso el desplazamiento forzado, situación que los hace establecer lazos de solidaridad, colaboración y apoyo mutuo, pero, que también puede constituirse en un círculo cerrado caracterizado por la falta de libertades individuales. Desde la perspectiva de Bourdieu (2000, p. 148), estas redes sociales pueden ser analizadas desde el concepto de capital social:

El capital social está constituido por la totalidad de los recursos potenciales o actuales asociados a la posesión de una red duradera de relaciones más o menos institucionalizadas de conocimiento y reconocimiento mutuos. En otras palabras, se trata de la totalidad de recursos basados en la pertenencia a un grupo.

En la misma dirección, Urrea, Arboleda y Arias (1999, p.183) asocian las redes sociales y redes familiares, las cuales las definen como

[...] el conjunto de individuos - mujeres y hombres- que reconocen y establecen, a través de varias generaciones y ciclos de vida nexos de parentesco de diferente tipo y grado, ya sea consanguíneo, ritual de vecindario o de sentido de pertenencia a una misma localidad, origen por adopción o por identidad religiosa entre otros.

Para el caso de la población desplazada, estas redes, cualquiera sean su tipo y grado, en principio, fueron de gran ayuda al llegar a la ciudad y en el proceso de inserción laboral.

En las experiencias laborales se puede leer que familiares y amigos se han convertido en mediadores para poder vincularse a un trabajo, o en el apoyo de iniciativas de trabajo individual. Este proceso ha tenido mayor viabilidad para aque- 
llas personas que ya han ido a Ipiales por primera vez, quienes ya conocen y han tenido algún tipo de relación con residentes de esta ciudad. En este caso, las redes familiares son claves para acceder a una oportunidad laboral. Las recomendaciones, la orientación, el apoyo económico fueron las principales manifestaciones de apoyo de la población residente hacia la población forastera.

También vale la pena mencionar las redes sociales que se construyeron durante el proceso migratorio entre integrantes de organizaciones de población desplazada. Por un lado, el compartir una situación similar y hacer parte de esta "comunidad" (Castillejo, 2000, p. 21) genera sentimientos de amistad y solidaridad entre ellos; pero también en algunas circunstancias se han generado disputas, desconfianzas y competencias. Las redes sociales que se constituyeron en el pasado se perciben más cercanas que aquellas que se establecieron entre población desplazada dentro de Ipiales.

Por otro lado, se identificaron las redes que se conforman con los residentes donde llegan a trabajar o a habitar. La calidad y dedicación en el trabajo les ha permitido establecer redes de amigos y conocidos que como jefes inmediatos los han recomendado para acceder a trabajos. Rosa (2010) narra sus vivencias así:

Yo empecé ahí donde me fui a arrendar una piecita. Me llevó a donde una señora a trabajar a lavarle ropa, ella me hizo contrato y yo iba cada ocho días a lavarle y así, entonces ella me recomendó donde otra amiga y así fui conociendo más gente, más gente y ya miran el trabajo de uno y no pues le dicen: "venga láveme a mí también, hágame aseo", o que se yo, "cuídeme los niños" y así va conociendo más gente, más gente y así claro y ahora gracias a Dios ya.

En estas características se identificaron tres tipos de redes sociales: 1. Las redes que se establecen antes de la llegada a la ciudad que fueron claves para que la población se instalara en la ciudad y se vinculara, así sea de manera temporal, a un trabajo. 2. Las redes que se establecen entre población con las misma condiciones de desplazamiento, las cuales son de gran ayuda en los procesos de inserción social. 3. Las redes que se establecen con residentes tanto en espacios laborales como en los espacios donde llegan a residir.

Al respecto de los tres tipos de redes sociales que se identifican en esta investigación, vale la pena retomar a Campdepadrós (2010, p. 3) sociólogo español en el análisis del papel de las redes sociales en la inmigración regular en España,cuando cita a Portes, Castell y Benton (1989) y otros autores:

Hay un debate en migraciones sobre los efectos positivos y negativos del capital social. Portes destaca entre los efectos positivos el control social de la solidaridad delimitada (bounded solidarity) y de la confianza exigible (enforceable trust), el 
apoyo familiar o los beneficios obtenidos más allá de los lazos familiares. Y entre los negativos la restricción del acceso a las oportunidades, la restricción a las libertades individuales, el exceso de celo sobre los miembros o el rebajar las expectativas de promoción social.

En este sentido, los tres tipos de redes sociales en el contexto del desplazamiento forzado en la ciudad de Ipiales, cuentan con diferentes características que van desde la solidaridad, ayuda mutua, integración y fortalecimiento de estas redes sociales, hasta la competencia, restricción al acceso de oportunidades y libertades individuales. Así se encontró que, si bien las redes sociales pueden ser consideradas como un potencial en los procesos de inserción social y laboral, también pueden generar rivalidades y luchas por un espacio en las dinámicas del mercado.

\section{REFLEXIONES FINALES}

El perímetro urbano del municipio de Ipiales es pequeño y allí se entretejen la vida rural y la vida urbana, donde converge una población pluriétnica y multicultural, compuesta por indígenas pastos, campesinos, mestizos, afrodescendientes, población urbana, migrantes de diferentes regiones del país, migrantes ecuatorianos y de otros países de Suramérica y, desde los años noventa, personas que han tenido que migrar debido al conflicto armado presente en Colombia por más de cincuenta años. Las principales fuentes de empleo y de ingresos para los habitantes de esta región son la agricultura y el comercio formal e informal.

La población en situación de desplazamiento forzado que llega a la ciudad de Ipiales, desde el momento de su arribo, día a día construye, negocia, reclama y disputa espacios y recursos para poder sobrevivir y establecer una forma de vida. Estas luchas por un lugar dentro de la ciudad han estado marcadas por serias dificultades asociadas a su condición de desplazamiento y a la estigmatización por parte de los residentes de la ciudad, quienes los señalan como pobres, delincuentes, informantes, y en el imaginario del residente representan peligro e inseguridad dentro de los sectores donde habitan y trabajan.

Uno de los procesos más difíciles en la llegada a la ciudad de Ipiales es el de inserción laboral. Una ciudad con escasas fuentes de empleo, con actividades agropecuarias minifundistas, de producción familiar y con un sistema comercial en el que se combinan trabajo formal e informal, legal e ilegal, que depende de las relaciones comerciales con el Ecuador y de la dinámica cambiaria ofrece un panorama complejo para la población. 
Las estrategias de inserción laboral son diferentes para mujeres y para hombres. En esta investigación se afianza la tesis de que el proceso de desplazamiento forzado, además de conllevar un proceso de reconfiguración territorial, también implica reconfiguración de los roles de los integrantes de la familia. Bajo las condiciones del desplazamiento forzado son las mujeres quienes en su mayoría asumen la responsabilidad económica y moral de sus familias. Son ellas quienes cuentan con mayores posibilidades de acceder a un empleo dentro de las urbes. Ellas se desempeñan en actividades asociadas al trabajo doméstico (lavado de ropa, cuidado de niños, aseo, preparación de alimentos) actividades artesanales, ventas ambulantes, ventas por catálogo. En estas actividades, ellas hacen uso de su creatividad, potencialidad y habilidad para lograr un lugar en el mercado laboral de Ipiales.

Ellos, por su parte, contaron con menos posibilidades que las mujeres, toda vez que suscitan mayor desconfianza dentro de los sectores generadores de empleo, son señalados como delincuentes, guerrilleros e informantes de los distintos grupos en oposición. Los trabajos a los cuales han logrado vincularse son: conductores de buses y taxis, mecánicos en talleres de mecánica automotriz, cargadores de bultos (coteros), en pequeñas fábricas de ladrillo, y algunos como asesores de la población en situación de desplazamiento.

Dos aspectos para destacar en relación con los procesos de inserción laboral son: las precarias condiciones laborales que tuvo que afrontar esta población y las estrategias de sobrevivencia asociadas a la creatividad e interés de la población para organizarse. En cuanto a lo primero, en la investigación se evidencian las precarias condiciones laborales a las cuales se enfrenta la población desplazada, asociadas a las largas jornadas laborales, las bajas remuneraciones, la inestabilidad laboral, la ausencia de afiliación a regímenes de seguridad social y, en general, el maltrato y la explotación laboral. En estos contextos se evidencia la doble victimización de hombres y de mujeres como personas víctimas del desplazamiento forzado, y expuestas a la explotación laboral en los sectores donde llegan a habitar.

Una de las consecuencias de las excesivas jornadas laborales es el abandono de sus familias, en especial de los hijos, quienes en algunos casos se quedan solos o a cargo de los vecinos, expuestos a riesgos como accidentes, abusos y maltratos etc. Los testimonios de la población desplazada dejan ver que las precarias condiciones laborales que afectan a la familia desplazada pueden repercutir en la generación de otras problemáticas sociales dentro de la ciudad, como violencia intrafamiliar, deserción escolar, delincuencia común, drogadicción y alcoholismo.

En cuanto a lo segundo, se destaca la creatividad de la población para poder vincularse laboralmente y el interés por la organización social. La misma situación 
de desplazamiento lleva a que la población se organice y desarrolle habilidades que ni ellos mismo conocían. Dentro del grupo investigado se destaca el liderazgo tanto de mujeres como de hombres, lo cual les ha permitido organizarse y desde allí gestionar ayudas y proyectos productivos promocionados por organizaciones como el SENA, Acción Social, Fundación Arco Iris y Pastoral Social.

Por otro lado, las redes familiares y sociales de la población desplazada con habitantes de la ciudad de Ipiales, son medios y estrategias que facilitan la inserción laboral y social de esta población. Este tipo de relaciones se convierten en referencias laborales y cartas de presentación ante posibles empleadores. Sin embargo, también se encuentran casos donde estas relaciones implican para la población desplazada compromisos dentro de grupos que limitan y cierran posibilidades laborales.

Finamente, en este escrito se deja abierto el debate para avanzar en la investigación sobre temas que merecen ser profundizados desde la academia y la investigación, como: el papel de las instituciones gubernamentales y no gubernamentales vinculadas con el desplazamiento forzado en los procesos de inserción laboral de la población; la relación entre remuneración y calidad de vida de la población dentro de las ciudades; las relaciones sociales y laborales de la población desplazada dentro de los lugares de trabajo; las implicaciones de la demanda laboral para la ciudad fronteriza; entre otros temas que permitan llenar vacíos en la investigación sobre población en situación de desplazamiento.

\section{BIBLIOGRAFÍA}

Acción Social (2008). Registro Único de Población Desplazada por municipios expulsores y receptores. Sistema Único de Población Desplazada (SIPOD).

Alsayyad, Nezar (2004). Urban Informality as a "New" Way of Life. A New Way of Life. GMS Urban Informality, Berkeley, pp. 7-31

Bourdieu, Pierre (2000). Poder, Derecho y Clases Sociales. Bilbao, editorial Desclee De Brouwer, S. A., $232 \mathrm{pp}$.

Campdepadrós Cullell, Roger (2010). El papel de las redes sociales en la inmigración irregular en España. X Congreso español de Sociología. Pamplona, 1-3 julio 2010. Grupo de trabajo 31: sociología económica, $24 \mathrm{pp}$.

Castells, Manuel (2008). La cuestión Urbana. 15ª Edición. Siglo XXI. México, 517 pp.

Castillejo, Alejandro (2000). Poética de lo otro. Antropología de la guerra, la soledad y el exilio interno en Colombia. Ministerio de Cultura, Instituto Colombiano de Antropología e Historia y COLCIENCIAS. Bogotá, ARFO editores LTDA, 296 pp. 
Inserción laboral de la población desplazada por el conflicto armado en la frontera colombo ecuatoriana

CCI -Cámara de Comercio de Ipiales- (2010). Pulso comercial: Compendio Estadístico del Movimiento Empresarial 2010. Coordinación de Proyectos y Gestión Empresarial, Cámara de Comercio de Ipiales, 32 pp.

CODHES -Consultoría para los Derechos Humanos y el Desplazamiento- (2009). Victimas emergentes: desplazamiento, derechos humanos y conflicto armado en 2008. Codhes Informa: Boletín informativo de la Consultoría para los Derechos Humanos y el Desplazamiento, N. 75, Bogotá, 22 de abril, 15 pp.

Corbetta, Piergiorgio (2003). Metodologías y técnicas de investigación social. Traducción de Marta Díaz Ugarte y Susana Díaz Ugarte. Madrid, McGraw-Hill/Interamericana de España, S. A. U., 448 pp.

CRC -Congreso de la República de Colombia- (1995). Ley 191. Por medio de la cual se dictan disposiciones sobre Zonas de Frontera. Bogotá, junio de 1995.

CRC -Congreso de la República de Colombia- (1997). Ley 387. Por la cual se adoptan medidas para la prevención del desplazamiento forzado; la atención, protección, consolidación y estabilización socioeconómica de los desplazados internos por la violencia en la República de Colombia. Bogotá, 24 de julio de 1997.

DANE -Departamento Administrativo Nacional de Estadística- (2005). Censo General 2005. Proyección de población 2005-2020.

De Soto, Hernando (1987). ¿Por qué importa la economía informal? Conferencia en la Universidad Católica de Chile el 17 de noviembre de 1987. Invitado por el Centro de Estudios Públicos, con ocasión del lanzamiento, en Chile, del libro El otro sendero. Esta conferencia ha sido editada por el CEP, 12 pp.

DNP -Departamento Nacional de Planeación-- (2011). Bases del Plan Nacional de Desarrollo 2010-2014. Prosperidad para todos. Versión radica ante el Congreso de la República el día 4 de febrero de 2011.

Gustín, Ana Rosa (2011). En la actividad ilegal se dedican más de mil familias de los municipios fronterizos de Ipiales, Cumbal, Aldana, Carlosama, Pupiales, entre otros, según la Policía Fiscal y Aduanera, Polfa de Ipiales. Diario del Sur. Edición del 2 de abril de 2011, Pasto.

Prado, Wilson (2011). Escasez de gas aumentó contrabando en la ciudad: Exigen normalizar distribución 25 el junio 2011. Diario del Sur. Edición del 25 de junio de 2011, Pasto.

El Colombiano (2001). Índice de pobreza en el país en 2010 fue de 40,2 por ciento. 24 de agosto del 2011.

Elyachar, Julia (2005). Markets of Dispossession NOGS, Economic Development, and the State in Cairo. Duke Uniersity Press. Durham and London, 274 pp.

Goffman, Erving (2006). Estigma. La identidad deteriorada. Buenos Aires-Madrid, Amorrortu Editores, $172 \mathrm{pp}$.

Grimson, Alejandro (2003). La nación en sus límites. Contrabandistas y exiliados en la frontera Argentina- Brasil. Barcelona, Gedisa Editorial, 251 pp. 
Ibáñez, Ana María y Moya, Andrés (2007). La población desplazada en Colombia: examen de sus condiciones socioeconómicas y análisis de las políticas actuales. Bogotá, Departamento Nacional de Planeación, 144 pp.

Ibáñez, Ana María y Velásquez Andrea (2008). El impacto del desplazamiento forzoso en Colombia. Condiciones socioeconómicas de la población desplazada, vinculación a los mercados laborales y políticas públicas. CEPAL, Serie Políticas sociales N. ${ }^{\circ}$ 145, Santiago de Chile, noviembre, $76 \mathrm{pp}$.

Lefebvre, Henri (1978). El derecho a la ciudad. Barcelona, ediciones Península. 169 pp.

Marcus, George E (2001). Etnografía en/del sistema mundo: el surgimiento de la etnografía multilocal. Traducción de Miguel Ángel Aguilar Díaz, Departamento de Sociología, Universidad Autónoma Metropolitana, Unidad Iztapalapa (UAM-I). Revista ALTERIDADES, 2001, Vol. 11, N. ${ }^{\circ} 22$, pp. 111-127.

Mertens, Donny (2004). Género, desplazamiento, derechos. En: Bello, Martha Nubia (ed.), pp. 197-204. Desplazamiento forzado dinámicas de guerra exclusión y desarraigo. Bogotá: editado por ACNUR y Universidad Nacional de Colombia, 460 pp.

POT -Plan de Ordenamiento Territorial- (2007). Plan Básico de Ordenamiento Territorial Ipiales Nariño 2000-2011. Alcaldía Municipal de Ipiales, 157 pp.

Portes, Alejandro (2001). Inmigración y metrópolis: reflexiones acerca de la historia urbana. Traducción de Eliézer Navarro. En: Migraciones internacionales, Vol. 1, N. 1 1, julio-diciembre, pp. 111-134

Portes, Alejandro y Haller, William (2004). La economía Informal. División de Desarrollo Social. CEPAL Organización de las Naciones Unidas Serie 100. Santiago de Chile, 55 pp.

Portes, Alejandro; Castells, M. y Benton, L. (1989). The Policy Implications of Informality, p. 298-311. En: The Informal Economy: Studies in Advanced and Less Developed Countries, edited by A. Portes, $\bar{M}$. Castells, and L. A. Benton. Baltimore, MD: The Johns Hopkins University Press, 360 pp.

Rakowski, Cathy A (1994). Contrapunto: the informal sector debate in Latin America. Published by State University of de New York, 336 pp.

Salcedo Fidalgo, Andrés (2006). Claiming Lands from the city: forced Displacement and the reconstruction in contemporary Colombia. Tesis Doctoral. Universidad de California, Irvine, EE. UU., 291 pp.

SERJE, Margarita (2005). El revés de la nación. Territorios salvajes, fronteras y tierras de nadie. Universidad de los Andes, Facultad de Ciencias Sociales, Departamento de Antropología Uniandes-Ceso, 294 pp.

Urrea, Fernando; Arboleda, Santiago y Arias, Javier (1999). Redes familiares entre migrantes de la costa pacífica a Cali. En: Revista Colombiana de Antropología, Volumen 35, enerodiciembre, pp. 180-241 
Inserción laboral de la población desplazada por el conflicto armado en la frontera colombo ecuatoriana

\section{ENTREVISTAS}

Alex (2010). Persona en situación de desplazamiento del municipio de Puerto Caicedo en el Departamento del Putumayo. Llega a Ipiales en el año 2002.

Carmelina (2010). Persona en situación de desplazamiento del Municipio de Puerres, en el Departamento de Nariño. Llega a Ipiales en el año 2002.

Carmen (2010). Persona en situación de desplazamiento del municipio de Ricaurte en el Departamento de Nariño. Llega a Ipiales en el año 2004.

Esperanza (2010). Persona en situación de desplazamiento del Municipio de Montes de María en el departamento de Bolívar. Llega a Ipiales en el año 2006.

Flavio (2010). Persona en situación de desplazamiento de la ciudad de San José de Isnos en el Departamento del Huila. Llega a Ipiales en el año 2007.

Leonor (2010). Persona en situación de desplazamiento del Corregimiento de La Victoria del Municipio de Ipiales, en el Departamento de Nariño. Llega a Ipiales en el año 2004.

Lilia (2010). Persona en situación de desplazamiento del Municipio de Cumbitara, Departamento de Nariño. Llega a Ipiales en el año 2005.

Martha (2010). Persona en situación de desplazamiento del Municipio de La Hormiga en el departamento del Putumayo. Llega a Ipiales en el año 2007.

Pablo (2010). Persona en situación de desplazamiento del Municipio de Puerto Asís en el Departamento del Putumayo. Llega a la ciudad en el año 2005.

Pastoral Social (2010). Entrevista y datos suministrados por la Señora Fanny Acosta funcionaria de la oficina de Pastoral Social Fronteriza.

Patricia (2010). Persona en situación de desplazamiento del Corregimiento de Monopamba en el Municipio de Puerres, Departamento de Nariño. Llega a Ipiales en el año 2006.

Perla (2010). Persona en situación de desplazamiento del Municipio de Caloto en el Departamento del Cauca. Llega a Ipiales en el año 2003.

Rosa (2010). Persona en situación de desplazamiento del Municipio de Santiago en el departamento del Putumayo. Llega a Ipiales en el año 2008. 
